\section{Estimates of HIV-1 incidence based on serological methods: a brief methodological review}

\author{
Estimativas de incidência da infecção pelo HIV-1 \\ baseadas em métodos sorológicos: uma sumária \\ revisão metodológica
}

\author{
1 Instituto Oswaldo Cruz, \\ Fundação Oswaldo Cruz, \\ Rio de Janeiro, Brasil. \\ 2 Instituto de Comunicação \\ e Informação Científica \\ e Tecnológica em Saúde, \\ Fundação Oswaldo Cruz, \\ Rio de Janeiro, Brasil. \\ Correspondence \\ M. G. Morgado \\ Instituto Oswaldo Cruz, \\ Fundação Oswaldo Cruz. \\ Av. Brasil 4365, Rio de Janeiro, \\ RJ 21045-900, Brasil. \\ mmorgado@ioc.fiocruz.br
}

\section{Abstract}

The paper reviews the serological methods employed in the estimation of HIV incidence based on cross-sectional studies, as well as the main findings from studies carried out in Brazil that have used such methods. Each method is briefly described, as well as their advantages and limitations. The different methods are also analyzed as a set of complementary but sometimes contradictory strategies under permanent criticism and review, still far from a gold standard. Finally, an additional question - central to the accurate monitoring of the AIDS epidemic using such methodsis discussed: whether the different methods should or should not be adjusted. The debate is open and controversy should be viewed as an unavoidable consequence of a very dynamic research field, informed by the progress in sciences as diverse as epidemiology, biostatistics, mathematical modeling and different branches of basic science, such as immunology, virology, and molecular biology.

HIV-1; HIV Infections; Incidence
Mariza Gonçalves Morgado 1

Francisco Inácio Bastos 2

\section{Introduction}

HIV is one of the most important emergent pathogens in the last century. Around 70 years after its introduction in the human population as a zoonosis from non-human primates, it has become a major public health problem throughout the world. World Health Organization (WHO) estimates point to 33.2 million (30.6-36.1 million) adults and children living with HIV in 2007, roughly $70 \%$ of them in Sub-Saharan Africa ${ }^{1}$. Latin America accounts for 1.7 million AIDS cases (1.5-2.1 million; 5\%) in this period. In Brazil, 630,000 individuals are estimated to be living with HIV/AIDS. This estimate has been quite stable since the beginning of this century ${ }^{2}$.

Although data on HIV seroprevalence are available for all countries in the world, the systematic assessment of incident cases through dedicated reporting systems is still limited to a few countries (e.g. the USA and Germany) that use serological approaches to estimate HIV incidence after repeated population-based studies 3,4 . The estimation of incidence rates at the population level is of paramount importance to assess the dynamics and trends of the HIV epidemic in order to implement adequate preventive measures and to monitor ongoing interventions and the putative impact of treatment at the population level, due to its impact on HIV infectivity and transmission 5. Moreover, studies aiming to evaluate the immune response and virus 
diversity in early infection are of great relevance for vaccine strategies.

The first methodological approaches used to estimate HIV incidence were based on the assessment of seroconversion in cohorts of HIVseronegative individuals, with the establishment of large cohorts in Western countries, such as the Multicenter AIDS Cohort Study (MACS), implemented in different research centers in the US, now celebrating its $25^{\text {th }}$ anniversary 6 , the Vancouver Injection Drug Users Study (VIDUS) in Vancouver, Canada 7, and the ALIVE study, also comprising injection drug users, and carried out since the late 1980s, in Baltimore, United States 8 .

This approach is very expensive and time consuming due to the necessity to follow large cohorts over time. Moreover, behavioral changes can take place during participation in this type of study, as an expected outcome of the adoption of standard of care interventions aiming to prevent HIV acquisition as mandated by ethical requirements of any study with human beings. Such interventions much likely reduce risky behaviors and seroconversion rates over time. Besides such limitations, secondary to the very characteristics of longitudinal studies with human beings, cohort studies also tend to select subgroups of individuals with particular characteristics (such as those more concerned about their health) 9 .

In this sense, cohort studies should not be viewed as a gold standard vis-à-vis estimates using biomarkers, but rather as studies subjected to their own specific biases 10 . As such, there is not a gold standard for assessing the validity of new strategies (either biological or epidemiological), and all strategies should be viewed as different attempts (with partial success) to circumvent the limitations and caveats posed by each different method.

In order to overcome such limitations to detect early and recent HIV infections, several methods based on the assessment of biological parameters have been developed over time to detect infection in both pre and post-seroconversion phases.

\section{Methods}

This paper summarizes the main methods that have been used to assess HIV seroincidence in cross-sectional studies worldwide. This section aims to be a tutorial for graduate students, clinicians, infectologists, and health managers, as well as researchers working in the fields of epidemiology, immunology, virology, and molecular biology.
The second part of the paper reviews the available evidence from Brazilian studies using such different methods and comprises a comprehensive review of all published studies available in the main bibliographic databases, such as PubMed, SciELO and Scopus, since the very implementation of such methods in Brazil up to September 2009.

\section{Results}

Major methods used in the assessment of HIV incidence in cross-sectional studies

Table 1 outlines the major serological approaches used to detect the pre and post HIV seroconversion phases. These approaches, based on biological parameters assessed in the sera of patients can be used in cross-sectional surveys as they are able to differentiate recent from long-term HIV-1 infections. In this section we will briefly describe their major characteristics and applications.

\section{- Pre-seroconversion}

During the immunological window, i.e., between infection and seroconversion, it is possible to detect HIV RNA, DNA and p24 antigens in absence of HIV antibodies 11 as follows: p24 antigen and DNA PCR, 26.4 days (95\% confidence interval - 95\%CI: 12.6-38.7); and RNA PCR, 31.0 days (95\%CI: 16.7-45.3). Further analyses with highly sensitive techniques reduced the time of RNA and p24 detection after HIV-1 infection (Table 1) to periods as short as 6 and 12 days, respectively 12 .

Early in 1995, p24 antigenemia and HIV antibodies were used as a two-step algorithm to detect the prevalence of p24 in absence of anti-HIV antibodies 13 . The HIV incidence rate was then calculated by using the classical relation between prevalence, incidence, and the duration of the period between the onset of p24 antigen detection and the first HIV antibodies.

The short window period for seroconversion is a limitation for the application of methods detecting HIV RNA or p24 antigen for the estimation of HIV incidence. Indeed, a very large number of HIV seronegative individuals should be tested to have the chance of identifying a few cases of seroconversion in order to get an accurate estimation of HIV incidence at the population level. The application of these methods to estimate HIV incidence is very limited in the literature.

Notwithstanding, the original insight from the American statistician Ron Brookmeyer to use two biomarkers emerging in different moments 
Major methods used in the estimation of HIV incidence based on cross-sectional surveys.

\begin{tabular}{|c|c|c|c|c|}
\hline Timing & Serological assay & Test for & Interval to & Window period (days) \\
\hline \multirow[t]{2}{*}{ Pre-seroconversion } & HIV-RNA & Plasma RNA & Detection & 5.612 \\
\hline & HIV p24 & Plasma p24 & Detection & 1212 \\
\hline \multirow[t]{6}{*}{ Seroconvertion } & LS-EIA & HIV Ab titer & $>>$ titer cutoff & $130-170$ \\
\hline & BED-CEIA & HIV Ab/total lgG & >> HIV Ab proportion & 153 \\
\hline & Avidity & HIV Ab Avidity & $>>$ Avidity cutoff & $125-14234$ \\
\hline & IgG3 isotype & Anti-p24 lgG3 isotype & $\begin{array}{c}\text { Undetectable anti-p24 lgG3 } \\
\text { isotype }\end{array}$ & 80 \\
\hline & IDE-V3 & Ratio ODsample /ODcontrol & $>>$ ratio & 18038 \\
\hline & INNO-LIA & Immunoblot & >> intensity of reaction & Not established 41 \\
\hline
\end{tabular}

Adapted from Parekh \& McDougal 16, including additional data from Bush et al. 12, Chawla et al. 34 , Barrin et al. 38 and Schüpbach et al. 41.

Ab: antibodies; BED-CEIA [BED (HIV-1 subtype gp41 antigens)]: capture enzyme immunoassay; IDE-V3: imunodominant epitope of the V3 region;

INNO-LIA: line immunoassay from innogenetics; LS-EIA: less sensitive enzyme immunoassay; >>: should be read here as a symbol for "increased reaction".

of the HIV infection over time paved the way for all subsequent assessments of HIV incidence based on cross-sectional studies, always profiting from the fact that incidence can be approximately deduced from available data on prevalence and the duration of a given infection (or non-transmissible medical condition). Besides the technical difficulties secondary to the short window period, one must also observe that the very nature of the statistical procedure imposes limitations on the accuracy of the estimates. As shown by Miettinen 14, the actual relation involves the prevalence odds instead of prevalence itself and the estimates have as a basic assumption the stability of the population under analysis, which is far from real in most cases (such issues are discussed in some detail in a former paper) 15 .

\section{- Post-seroconversion}

In order to improve the serological estimates of HIV incidence, serological methods able to discriminate recent from long-term seroconversion with HIV, denominated as "serological testing algorithm for recent HIV seroconversion" (STARHS) have been developed over time, as reviewed by Parekh \& McDougal 16 and Murphy \& Parry 17.

While in the pre-seroconversion phase the methods are based on the detection of p24 antigen and/or viral RNA, in the post HIV seroconversion phase the STARHS are based on differences on anti-HIV antibody concentration, proportion, affinity, avidity and immunoglobulin isotype, which are parameters associated to the matura- tion of the immune response to target antigens (Table 1). Although developed for distinguishing recent from long-term HIV infection, in general the STARHS are not considered sensitive enough to be used at the level of individual cases. Their major applications rely on population-based studies, for estimating the rate of acquisition of new infection, or incidence rate based on crosssectional serosurveys 17 .

\section{Detuned assay}

The first serological strategy used to identify recent seroconversion in a cross-sectional population, developed by Janssen et al. 18, was based on a sensitive/less sensitive testing algorithm using commercial ELISA assays (S/LS EIA). This approach, also known as detuned assay, was based on the differences on HIV-antibody concentrations between recent and long-term HIV infection. For this purpose, the firstly developed detuned assay was a modification of the commercial HIV-1 antibody assay 3A11 (Abbott), increasing the serum dilution (1:20.000) and shortening incubation times to render it less-sensitive (3A11-LS) in detecting HIV-1 antibodies. HIVpositive individuals with low titer antibodies to HIV antigens, as seen in early infections, gave results below a pre-determined threshold cutoff in the LS assay, but positive in the S assay, and were considered as recent infections. The window period was defined based on serial samples from known seroconverters, and was found to be 129 days (95\%CI: 109-149 days). Due to the nature of this method, an internal calibrator and additional control specimens, provided by 
the Centers for Disease Control and Prevention (CDC), were requested to determine the cut-off and to monitor the assay performance 16. Differences on the window period between HIV-1 subtype infections were however detected in two studies conducted in Thailand, comparing Thai subtype B (B') and CRF01_AE infected individuals. These differences were also detected between the two commercial kits adapted for the S/LS detuned assay. Thus, a window period of 155 days (95\%CI: 128-189 days) was found for subtype B using the HIV-1 antibody assay 3A11, but it was of 270 days (95\%CI: 187-349 days) for CRF01_AE specimens 19. Similarly, Vironostika-LS EIA results showed a mean window period of 239 days (95\%CI: 208-287 days) for subtype B' and 356 days (95\%CI: 318-402 days) for CRF01_AE samples from Thailand 20. These results demonstrate that both methods have different performances in detecting recent seroconversion between different HIV-1 subtypes. Although this method was applied in several contexts and populations 16,17, limitations in terms of estimates for different HIV subtypes, as well as the availability of commercial kits are limiting issues.

\section{- BED-CEIA}

A new approach to detect HIV-1 recent infection was developed by Parekh et al. 21 and used a branched peptide containing the gp41 immunodominant sequences from HIV-1 subtypes B, E (CRF01_AE), and D, in a competitive capture EIA, denominated BED-capture enzyme immunoassay (BED-CEIA). This assay is based on the gradual increase on the proportion of anti-HIV-1 specific IgG in the total IgG, as observed along the maturation of the immune response to a given antigen. In order to define the cut-off to distinguish recent from long-term infections, the BED-CEIA normalized optical density (OD-n) was calculated (ODspecimen/ODcalibrator), using a calibrator specimen, to 1.0 OD-n for a seroconversion period of 160 days. Separate analysis of B and E subtype specimens yielded the same optimal OD-n threshold and similar seroconversion periods and the assay was further validated in African specimens 21. Variations in the window period have been observed for some subtypes (mean of 153 days for subtypes A to E), however if these differences are due to the assay or other confounding factors related to the population structure and other characteristics of the local epidemics, those remain to be determined 16 .

This assay has been largely used in multiple cross-sectional studies to identify recent infections and to estimate HIV incidence in differ- ent countries and epidemiological scenarios $22,23,24,25,26$. Indeed, this method was applied in a national study to estimate HIV incidence in the US ${ }^{3}$.

Taking together, these studies provide trends of incidence and identify associated risk factors, which may contribute to establish preventive measures to control HIV-1 infection. The BED-CEIA is commercially available (Calypte Biomedical, US) and the CDC provides periodic proficiency panels to assess the performance of this technique in the US and international laboratories for both sera and dried blood spots (DBS). Based on some evidence that the BED-CEIA approach misclassifies as recent a substantial minority of long-term infections and consequently leads to overestimation of the incidence rates, the UNAIDS (The United Nations Joint Programme on HIV/AIDS) Reference Group 27 recommended that the BED-assay should not be used for routine surveillance applications, nor for absolute incidence estimates, nor monitoring trends. Among other studies, an unexpectedly high incidence of $6.1 \%$ /year 95\%CI: 4.2-8.0 was observed in Masaka and 6.0\%/year (95\%CI: 4.3-7.7) in Kakira, Uganda, while prospective incidence data in Masaka from the same population were found to be $1.7 \%$ /year before and $1.4 \%$ /year after the study 28 . In order to improve the accuracy of this method, different types of adjustments have been suggested and will be discussed further in this article 29,30.

\section{- Avidity index method}

Increases in the antibody avidity are observed along the maturation of the immune response to a given antigen. Differences in the IgG avidity to HIV-1 antigens have been described as a useful tool to discriminate recent from long-term HIV-1 infections $31,32,33$. In order to measure the differences on IgG avidity, a commercial method used for HIV diagnostic (AxSYM HIV1/2gO test; Abbott) was modified and the serum samples were tested in parallel diluted in phosphate-buffered saline and in $1 \mathrm{M}$ guanidine. A low avidity (less than $50 \%$ ) was found in recently infected patients (less than 6 months), compared to longterm infected patients (more than 12 months), who had a higher avidity (80 to $100 \%$ ) 31 . The avidity index $[\mathrm{AI}]$, determined as the ratio of the sample/cut-off value for the guanidine aliquot to that of the phosphate-buffered saline aliquot, was calculated based on serum samples with well documented dates of HIV infection, showed that the mean AIs were $0.68 \pm 0.16$, within 6 months of infection, and $0.98 \pm 0.10$ after 6 months. An AI of $<0.90$ correctly identified $88.2 \%$ of recent infec- 
tions, but misclassified as recent infections $13.2 \%$ of serum samples collected afterward ${ }^{33}$. Avidity indices of $\leq 0.75$ and $\leq 0.80$ consistently identified seroconversion within 125 (95\%CI: 85-164) and 142 (95\%CI, 101-183) days, respectively ${ }^{34}$. AIDSdefining conditions were also found to interfere with the accuracy of this method, as previously described for the detuned and BED-CEIA assays. However, low CD4 counts and viral load, as well as antiretroviral treatment, had no effect in the AI 32. Comparative studies of the avidity assay with detuned or BED-CEIA showed similar performances for the three assays to identify recent infections in a region where subtype B predominates 35 . More recently, evaluating known seroconversion rates of HIV-seropositive samples from Uganda, where subtypes D and A predominate, the mean $\mathrm{AI}$ found for patients with recent infection was $0.55 \pm 0.21$, while AI of $0.93 \pm 0.14$ was detected for those from long-term infections 36 . In this study, a sensitivity of $85.2 \%$ and a specificity of $85.4 \%$ for a cut-off of 0.80 were observed, with no association between HIV subtypes and misclassification, suggesting that this method can be used in field studies in both $B$ and non- $B$ endemic regions.

\section{- Immunoglobulin isotype changing}

Based on the analysis of serial HIV-1 seropositive samples with known seroconversion dates by isotype-specific western blot it was possible to identify differences on antigen reactivity according to the IgG isotype ${ }^{37}$. While IgG1 was directed toward a range of viral proteins, IgG3 was basically directed to p17 and p24 antigens and, as measured by densitometry, the intensity of the IgG3 anti-p24 response was highest early after infection (days 58 and 86 post-infection), declining thereafter. This observation led to the isolation of p24 protein and further standardization of an in house IgG3-specific anti-p24 enzyme-linked immunoabsorbent assay able to discriminate recent (1-4 months) from long-term HIV-1 infection. As of our knowledge, no application of this method to estimate HIV-1 incidence in the field has been published so far.

\section{- gp41 IDE - gp120V3 assay}

In order to overcome issues related to the availability and utilization of commercial kits, an inhouse indirect enzyme-linked immunosorbent assay was developed to quantify antibodies toward four HIV-1 antigens: consensus peptides of the immunodominant epitope of gp41 (IDE), consensus V3 peptides, recombinant integrase, and recombinant p24 38. Among them, the IDE and V3 peptides were selected due to their capacity for discriminating recent $(<6$ months) from long-term infections. The results are expressed as a ratio of the optical density (OD) sample/OD negative control sera, and the median ratios for antibodies to IDE and V3 were shown to be more than 20-fold higher for sera from chronically infected patients than for sera from recently infected patients 38 . The IDE antigen corresponded to two consensus oligopeptides of 30 amino acids, one HIV-1 group $\mathrm{M}$ and one from subtype D, while a mixture of five $\mathrm{V} 3$ peptides representing consensus sequences of clades A, B, C, D, and CRF01-AE. Combined quantification of antibody binding to these antigens led to the identification of recent infection with high sensitivity (88.3\%) and specificity (97.6\%), when analyzing 971 serum samples from HIV-1 positive untreated patients in France 38 . This assay was also validated for dried blood spots, which improves its utility for population studies. Indeed, it has been used to estimate the incidence rate of HIV-1 infection in France 39. However, in a study conducted in Ivory Coast 40, although the IDE-V3 technique had a specificity of $96.3 \%$ for HIV recent infections, a sensitivity of around $40 \%$ was observed with this method, which would suggest that differences on HIV-1 subtype infections could compromise the accuracy of this method.

\section{- HIVI/II confirmatory line immunoassay}

More recently, the ability of an HIV confirmatory line immunoassay (INNO-LIA HIVI/II) was tested to distinguish recent from long-term HIV infection ${ }^{41}$. The authors evaluated the performance of various algorithms for detecting recent infections, based on reactivity, and classified them into one of six possible intensity scores of reaction to five HIV antigens measured in the western blot. They analyzed 356 serum samples, with well documented recent and long-term infections to define the sensitivity and specificity of the proposed algorithms as compared to the HIV-1 BED-CEIA. In general, the specificity of these INNO-LIA algorithms was above $90 \%$, and higher than BED-CEIA in the study $(80.1 \%)$, but the sensitivity, even after several adjustments, was not satisfactory. According to the authors, recency information could be extracted from INNO-LIA based confirmatory assay at no extra cost. However, in general this confirmatory procedure is not available in developing countries due to its high cost. No additional papers using this approach have been made available so far, making its application to the estimation of HIV incidence still tentative. 
Application of serological methods to estimate HIV-1 incidence in Brazil

The above discussed serological assays delineated to detect recent HIV-1 infections have been implemented in Brazil since the end of the 1990s as new tools to estimate the incidence rates of HIV-1 in different scenarios. However, no national data about the incidence of HIV-1 infection have so far been made available. The studies were mainly conducted in the Southeastern region of the country and employed the serologic testing algorithm for detecting recent HIV seroconversion (STARHS), previously denominated sensitive/less sensitive assay. Using this approach, an estimated HIV seroincidence of 1.9 (95\%CI: $0.9 \%-3.9 \%)$ and 2.8 (95\%CI: $1.4 \%-5.3 \%)$ per 100 person-years among high-risk heterosexual women and men seen at an HIV testing site in Rio de Janeiro in 1998 42. A few years later 43, an update of the former analysis found similar results, with an estimated HIV incidence among heterosexual men (1.62\%; 95\%CI: 0.61-3.52) and women (1.5\%; 95\%CI: 0.45-3.69), screened in 2002. However, a higher incidence rate, of almost seven fold, was observed for homosexual men, with a seroincidence of $10.89 \%$ (95\%CI: 4.28-24.81) 43 . A non-significant increase of recent HIV-1 infections ( $0 \% v s .0 .8 \%$ ) was observed among injection drug users (IDU) and ex-IDU 44,45 surveyed in 1994-96 and 1999-2001, in Rio de Janeiro. Similar studies were conducted in Sao Paulo, estimating the incidence of HIV-1 infection in inmates 46 , cocaine users 47 , and among people seeking HIV diagnosis in voluntary centers for counseling and testing from Santos (São Paulo State) 48 and Sao Paulo city 49,50 . In the former study, sera collected between 1996 and 1999 in Santos yielded an overall estimated HIV incidence of $2 \%$ (95\%CI: 1.1-3.5), with $1.2 \%$ (95\%CI: 0.5-2.6) in women and $2.7 \%$ (95\%CI: 1.3-5.0) in men, quite similar to the results obtained in a voluntary center for counseling and testing in Rio de Janeiro for the same period 42 . The incidence of HIV-1 infection based on the STARHS has already been assessed in pregnant women from São Paulo 51, Rio de Janeiro and Porto Alegre (Rio Grande do Sul State). In the former, a cross-sectional study including samples collected from 1999 to 2002 in São Paulo had an incidence of HIV-1 infection of 0.2 per 100 pregnant women per year (95\%CI: 0.041-0.608). Similar results were obtained by our group for pregnant women from Rio de Janeiro $(0.41 \%$; IC95\%: 0.11-0.72), diagnosed for HIV infection at delivery in the same time period, whereas HIV incidence of $1.93 \%$ (IC95\%: 0.88-2.97) was observed in southern Brazil (Morgado MG, unpublished data).
Incidence of HIV-1 infection was also estimated among blood donors from São Paulo 52, Brazil (2.7 per 10,000 person-years), in a study comparing first time community and replacement blood donors from 1995 and 2001. Moreover, around $21 \%$ of potential recent infections were detected using BED-CEIA among HIV-1 seropositive discharged blood units from Brazilian blood donors 53 .

More recently, BED-CEIA has been employed in Brazil for estimating HIV incidence and to assess the molecular characterization of newly identified HIV-1 infections in people seeking HIV diagnosis in voluntary centers for counseling and testing in Rio de Janeiro 54, and Curitiba (Paraná State) 55, and in a Public Health Laboratory serving communities with high prevalence of HIV infection in Santa Catarina State (Camboriú and Itajaí) 56. Indeed, a preponderance of subtype $\mathrm{C}$ was detected among males with recent infection in Curitiba, and the overall incidence in this study was of 2.86 persons/years (95\%CI: 1.04-4.68). Similar results were obtained for the two Santa Catarina cities, that presented an overall incidence estimate of 2.6 persons/year (95\%CI: \pm 0.8$) 56$, in a virological scenario where subtype $\mathrm{C}$ predominates. Considering the $\mathrm{WHO}$ criticisms 30 about the sensitivity and specificity of the BED-CEIA to estimate HIV incidence in epidemiological scenarios including non-B HIV-1 subtypes, in a preliminary study we proposed a criterion based on the matching results of two assays (BED-CEIA and Avidity index) aiming to improve the accuracy of these serological approaches to estimate HIV incidence rates 57.

One major limitation of most Brazilian studies is secondary to the small sample size (and then large confidence intervals and less accurate estimates), as well as some degree of heterogeneity in some studies, such as the ones carried out by our research group on both active and former injection drug users (as stated in the original protocol, from WHO, but not necessarily defining a homogeneous sample) 44,45 .

\section{Final remarks}

Incidence estimates by serological assays using cross-sectional surveys are very attractive as such studies are much cheaper than longitudinal studies, much simpler to be implemented and less subject to some of the usual bias affecting longitudinal studies. Such biases comprise the decrease of both risk behaviors and seroincidence over time as a consequence of the full implementation of state-of-the-art interventions aiming to prevent new infections (as mandated 
by ethical requirements in any study with human beings) and the loss for follow-up (usually a differential loss), affecting the most vulnerable and/ or those most likely to be infected vis-à-vis those who tend to remain in the cohort over time, who are more likely to be concerned with their health and to adopt safer behaviors, as discussed by Harrison et al. 9 .

However, several drawbacks may compromise the accuracy of such biomarkers as tools for estimating HIV incidence in cross-sectional studies. In general, false positive and or false negative results have been described for all the available methods, biasing, in opposite directions, the estimates of incidence of the samples under study, with obvious consequences for its extrapolation for the reference population. Moreover, differences on HIV-1 subtype infections, low CD4 counts, long term undetectable viral loads, antiretroviral therapy, total IgG concentration, among others, are also associated to the misclassification of recent infections. Due to concerns about studies based on the use of BED-CEIA, conducted in scenarios with high HIV prevalence and/or viral diversity 27 , different adjustments have been proposed aiming to improve its accuracy for HIV estimates. One such adjustment proposes "the exclusion of certain specimens on clinical grounds, by relying on trend differences rather than absolute incidence estimates, by secondary confirmatory testing, or by analytic adjustments for misclassification" 29 (p. 945) and a second strategy adjusts some parameters, with "further estimates of epsilon and of the window period", in order to avoid misclassification of subtype C infected individuals 30 (p. 511).

However, based on the recent literature, there is no consensus of whether or not the proposed adjustments may improve the accuracy of HIV incidence estimates. The pioneer of such strategies from the perspective of statistical methods, Ron Brookmeyer, has recently published a paper where he discusses at length his position against the available adjustments 10 . One must observe, however, that his position was criticized by three research groups (Hargrove 58, Welte et al. 59 and McDougal 60), with a further treplica by Brookmeyer, who maintained his point of view despite the criticisms 61 .

McWalter \& Welte 62 further developed the position outlined in their letter in response to Brookmeyer's paper, and took a firm position in favor of adjustment. They compared the accuracy of their adjustment strategy with the adjustment strategies proposed by the authors of the other two letters in response to Brookemeyer's paper (i.e. Hargrove 58 and McDougal 60, and their respective research teams). The authors conclude that their own strategy is the one which can work under the less restrictive assumptions. One must observe that in spite of their position, the authors admit themselves in their final remarks: "all the methods make the assumption that survival for assay non-progressors and assay progressors is the same. As we have shown, relaxing this assumption means that the long-term specificity becomes epidemic state dependent" 62.

From a complementary perspective, a recent paper by Hallet et al. 63, simulating scenarios for the AIDS epidemic in six different African countries, highlighted another caveat putatively associated with the dynamics of each specific epidemic. For Hallet et al. 63 the key question to be urgently evaluated is secondary to whether misclassification based on the use of BED-CEIA may or may not vary over time elapsed since primary infection. The authors conclude that in the case of a non-stationary misclassification bias (i.e. a bias that may vary over time, in this specific case, hypothetically increasing over time), estimates would be influenced by the different trajectories of specific epidemics in each given place, as well as by the underlying demographic composition of each affected population. If such hypothesis proves to be a valid one (i.e. in the case that bias actually increases over time since primary infection), post-assay adjustments will not improve the accuracy of the estimates using BED.

The association of more than one biomarker to improve the estimates of HIV incidence has also been recently proposed. In this sense, a good agreement (90\%) between BED-CEIA and Vironostika S/LS methods was obtained for the classification of recent HIV-1 infection 64, when compared to repeat testing in a population of men having sex with men from San Francisco, US. Lower agreement 65 , however, was observed when Vironostika S/LS and Avidity assays were compared to identify recent HIV-1 infections among patients entering the Johns Hopkins Hospital Emergency Department in 2001 and 2003. All discrepant cases had undetectable viral load, that were identified as recent by the Vironostika S/LS assay but not with the Avidity assay, indicating that viral suppression affects the performance of cross sectional incidence assays based on antibody titer. Similar results were obtained for four long-term non-progressors/elite controllers from Brazil, who gave results compatible with recent infection based on the competitive BED-CEIA assay, whereas only 2 out of 4 were misclassified when using the avidity assay 66 .

The application of four available tests (BEDCEIA, Vironostika, Avidity index, and IDE-V3) to estimate HIV-1 incidence in West Africa, where high prevalence is observed $(10 \%)$ in a virologi- 
cal scenario of non-subtype B infections, generated very discrepant results, varying from $1.2 \%$ (IDE-V3) to $11.2 \%$ (AI) ${ }^{40}$. In this study they tested a panel of samples of known seroconversion dates and assessed misclassification, showing that incident cases were more likely to be observed among patients infected for more than 180 , but less than 360 days.

Recently (April 22-24/2009), the World Health Organization convened a meeting in order to standardize the terminology and statistical methods used to adjust (or not adjust) the different HIV assays. Although consensus was not reached respecting the statistical methods, a brand new terminology was advanced in the sense that "the meaning of 'recently infected' [would be] defined by the assay itself (...). This removes the need to speak of sensitivity and specificity of the assay in the usual diagnostic sense, as the assay is no longer a proxy for any other condition" 67 (p. 19). The WHO Working Group suggested to standardize the terminology, beginning with a new, broader definition of the very techniques and methods used in the estimation of recent infection as RITA (Recent Infection Testing Algorithm), defined as follows: "A combination of specific laboratory and/or other methods that is intended to classify individuals as positive or negative for the state of 'recent infection', for the purposes of estimating HIV incidence" 67 (p. 7).

A brand new development was recently proposed by Karon et al. 68, in a paper coauthored by Ron Brookmeyer, the leading proponent of the use of back-calculation as a key tool for estimating HIV incidence from reported AIDS cases, a strategy later compromised by the change in surveillance AIDS and the widespread dissemination of anti-retrovirals, in both high-income countries and middle-income countries such as Brazil and Thailand. As mentioned before, Brookmeyer was also the originator of the methods using biomarkers to estimate HIV incidence in the context of cross-sectional studies (as dis- cussed at length in a former paper 15). The new method advanced by Karon et al. ${ }^{68}$ profit from both previous insights, and propose a new surveillance strategy to be adopted at the macrolevel (for regions or even countries), "in order to estimate the probability that an infected person will be detected as recently infected" 68 (p. 4617), accounting from the intrinsic variability in terms of his/her testing behaviors (e.g. testing frequency, the availability of previous tests and the reporting of results to those people). In sum, the method estimates "the number of persons detected as recently infected divided by the estimated probability of detection" 68 (p. 4617). Notwithstanding the inventiveness of this new strategy, old phantoms still haunt it, such as the accuracy of the window periods defined by the different methods/algorithms, as discussed by WHO 67 , and the very availability of information about biomarkers at the population level, which could be partially addressed by multiple imputations. It is still precocious to say whether such new strategy will be found to be a valid method in concrete situations.

In sum, methods aiming to estimate HIV incidence have progressed a lot in recent years, but are unfortunately still far from optimal, with no consensus among the experts in terms of a gold standard either respecting the methods themselves or the best way to adjust (or not adjust) them. As observed by the person responsible for the original statistical reasoning informing all such methods, Ron Brookmeyer ${ }^{61}$, there is also no gold standard in the context of longitudinal studies, which are subjected to different but relevant biases.

Paraphrasing the philosopher of science Hacking 69 (p. 11), "the taming of chance" is an essential feature of the contemporary world, constituting the "very stuff of the fundamental processes of nature and of society". However, the very attempt of taming chance is far from straightforward and simple. 


\section{Resumo}

O artigo revisa os métodos sorológicos utilizados na estimação da incidência da infecção pelo HIV baseada em estudos seccionais, assim como os principais achados de estudos conduzidos no Brasil que utilizaram estes métodos. Cada um dos métodos foi descrito sucintamente, assim como suas vantagens e limitações. Os diferentes métodos foram ainda analisados enquanto um conjunto de estratégias complementares, por vezes, contraditórias, sob permanente crítica e revisão, ainda longe de um padrão-ouro. Finalmente, uma questão adicional-essencial a um monitoramento acurado da epidemia por meio desses métodos - é discutida: devem tais métodos ser ajustados ou não? O debate segue em aberto e deve ser visto como um desdobramento inevitável de um campo de pesquisa particularmente dinâmico, informado pelos avanços de ciências as mais diversas, como a epidemiologia, a estatística e a modelagem matemática, além das várias áreas da ciência básica, como imunologia, virologia e biologia molecular

HIV-1; Infecções por HIV; Incidência

\section{Contributors}

M. G. Morgado and F. I. Bastos made substantial contributions to the conception and design, acquisition of data, analysis and interpretation of data; drafting the article or revising it critically for important intellectual content; and final approval of the version to be published.

\section{References}

1. Joint United Nations Programme on HIV/AIDS. 2008 report on the global AIDS epidemic. Geneva: Joint United Nations Programme on HIV/AIDS; 2008.

2. Bastos FI, Nunn A, Hacker MA, Malta M, Szwarcwald CL. AIDS in Brazil: the challenge and the response. In: Celentano DD, Beyrer C, editors. Public health aspects of HIV/AIDS in developing countries: epidemiology, prevention and care. New York: Springer International; 2008. p. 629-54.

3. Hall HI, Song R, Rhodes P, Prejean J, An Q, Lee LM, et al. Estimation of HIV incidence in the United States. JAMA 2008; 300:520-9.

4. Bätzing-Feigenbaum J, Loschen S, Gohlke-Micknis S, Zimmermann R, Herrmann A, Kamga Wambo O, et al. Country-wide HIV incidence study complementing HIV surveillance in Germany. Euro Surveill 2008; 13:pii:18971.
5. Porco TC, Martin JN, Page-Shafer KA, Cheng A, Charlebois E, Grant RM, et al. Decline in HIV infectivity following the introduction of highly active antiretroviral therapy. AIDS 2004; 18:81-8.

6. MACS celebrates its 25th anniversary. AIDS Patient Care STDS 2009; 23:486-7.

7. Tyndall MW, Craib KJ, Currie S, Li K, O'Shaughnessy MV, Schechter MT. Impact of HIV infection on mortality in a cohort of injection drug users. J Acquir Immune Defic Syndr 2001; 28:351-7.

8. Nelson KE, Vlahov D, Solomon L, Cohn S, Muñoz A. Temporal trends of incident human immunodeficiency virus infection in a cohort of injecting drug users in Baltimore, Md. Arch Intern Med 1995; 155:1305-11. 
9. Harrison L, Dunn DT, Green H, Copas AJ. Modelling the association between patient characteristics and the change over time in a disease measure using observational cohort data. Stat Med 2009; 28:3260-75.

10. Brookmeyer R. Should biomarker estimates of HIV incidence be adjusted? AIDS 2009; 23:485-91.

11. Busch MP, Lee LL, Satten GA, Henrard DR, Farzadegan $\mathrm{H}$, Nelson KE, et al. Time course of detection of viral and serologic markers preceding human immunodeficiency virus type 1 seroconversion: implications for screening of blood and tissue donors. Transfusion 1995; 35:91-7.

12. Busch MP, Glynn SA, Stramer SL, Strong DM, Caglioti S, Wright DJ, et al. A new strategy for estimating risks of transfusion-transmitted viral infections based on rates of detection of recently infected donors. Transfusion 2005; 45:254-64.

13. Brookmeyer R, Quinn TC. Estimation of current human immunodeficiency virus incidence rates from a cross-sectional survey using early diagnostic tests. Am J Epidemiol 1995; 141:166-72.

14. Miettinen OS. Theoretical epidemiology. New York: John Wiley \& Sons; 1985.

15. Bastos FI. "Get back to where you once belonged": monitoring the AIDS pandemic in the 21st century. Cien Saúde Coletiva 2008; 13:1719-27.

16. Parekh BS, McDougal JS. Application of laboratory methods for estimation of HIV-1 incidence. Indian J Med Res 2005; 121:510-8.

17. Murphy G, Parry JV. Assays for the detection of recent infections with human immunodeficiency virus type 1. Euro Surveill 2008; 13:pii:18966.

18. Janssen RS, Satten GA, Stramer SL, Rawal BD, O'Brien TR, Weiblen BJ, et al. New testing strategy to detect early HIV-1 infection for use in incidence estimates and for clinical and prevention purposes. JAMA 1998; 280:42-8.

19. Parekh BS, Hu DJ, Vanichseni S, Satten GA, Candal D, Young NL, et al. Evaluation of a sensitive/ less-sensitive testing algorithm using the 3A11LS assay for detecting recent HIV seroconversion among individuals with HIV-1 subtype B or E infection in Thailand. AIDS Res Hum Retroviruses 2001; 17:453-8.

20. Young CL, Hu DJ, Byers R, Vanichseni S, Young NL, Nelson R, et al. Evaluation of a sensitive/less sensitive testing algorithm using the bioMérieux Vironostika-LS assay for detecting recent HIV-1 subtype B' or E infection in Thailand. AIDS Res Hum Retroviruses 2003; 19:481-6.

21. Parekh BS, Kennedy MS, Dobbs T, Pau CP, Byers R, Green T, et al. Quantitative detection of increasing HIV type 1 antibodies after seroconversion: a simple assay for detecting recent HIV infection and estimating incidence. AIDS Res Hum Retroviruses 2002; 18:295-307.

22. Hu DJ, Vanichseni S, Mock PA, Young NL, Dobbs T, Byers Jr. RH, et al. HIV type 1 incidence estimates by detection of recent infection from a cross-sectional sampling of injection drug users in Bangkok: use of the IgG capture BED enzyme immunoassay. AIDS Res Hum Retroviruses 2003; 19:727-30.
23. Nesheim S, Parekh B, Sullivan K, Bulterys M, Dobbs T, Lindsay M, et al. Temporal trends in HIV type 1 incidence among inner-city childbearing women in Atlanta: use of the IgG-capture BED-enzyme immunoassay. AIDS Res Hum Retroviruses 2005; 21:537-44.

24. Wolday D, Meles H, Hailu E, Messele T, Mengistu Y, Fekadu M, et al. Temporal trends in the incidence of HIV infection in antenatal clinic attendees in Addis Ababa, Ethiopia, 1995-2003. J Intern Med 2007; 261:132-7.

25. Priddy FH, Pilcher CD, Moore RH, Tambe P, Park MN, Fiscus SA, et al. Detection of acute HIV infections in an urban HIV counseling and testing population in the United States. J Acquir Immune Defic Syndr 2007; 44:196-202.

26. Mermin J, Musinguzi J, Opio A, Kirungi W, Ekwaru JP, Hladik W, et al. Risk factors for recent HIV infection in Uganda. JAMA 2008; 300:540-9.

27. UNAIDS Reference Group on estimates, modelling and projections - statement on the use of the BED assay for the estimation of HIV-1 incidence for surveillance or epidemic monitoring. Wkly Epidemiol Rec 2006; 81:40.

28. Karita E, Price M, Hunter E, Chomba E, Allen S, Fei L, et al. Investigating the utility of the HIV-1 BED capture enzyme immunoassay using crosssectional and longitudinal seroconverter specimens from Africa. AIDS 2007; 21:403-8.

29. McDougal JS, Parekh BS, Peterson ML, Branson BM, Dobbs T, Ackers M, et al. Comparison of HIV type 1 incidence observed during longitudinal follow-up with incidence estimated by crosssectional analysis using the BED capture enzyme immunoassay. AIDS Res Hum Retroviruses 2006; 22:945-52.

30. Hargrove JW, Humphrey JH, Mutasa K, Parekh BS, McDougal JS, Ntozini R, et al. Improved HIV-1 incidence estimates using the BED capture enzyme immunoassay. AIDS 2008; 22:511-8.

31. Le Guillou H, Le Meur A, Bourdon S, Riou M, Loison J, Fialaire P, et al. Avidité des anticorps: application au diagnostic d'infection récente à VIH1. Ann Biol Clin (Paris) 2001; 59:41-7.

32. Suligoi B, Galli C, Massi M, Di Sora F, Sciandra M, Pezzotti P, et al. Precision and accuracy of a procedure for detecting recent human immunodeficiency virus infections by calculating the antibody avidity index by an automated immunoassaybased method. J Clin Microbiol 2002; 40:4015-20.

33. Suligoi B, Massi M, Galli C, Sciandra M, Di Sora F, Pezzotti P, et al. Identifying recent HIV infections using the avidity index and an automated enzyme immunoassay. J Acquir Immune Defic Syndr 2003; 32:424-8.

34. Chawla A, Murphy G, Donnelly C, Booth CL, Johnson M, Parry JV, et al. Human immunodeficiency virus (HIV) antibody avidity testing to identify recent infection in newly diagnosed HIV type 1 (HIV-1)-seropositive persons infected with diverse HIV-1 subtypes. J Clin Microbiol 2007; 45:415-20. 
35. Gupta SB, Murphy G, Koenig E, Adon C, Beyrer C, Celentano D, et al. Comparison of methods to detect recent HIV type 1 infection in cross-sectionally collected specimens from a cohort of female sex workers in the Dominican Republic. AIDS Res Hum Retroviruses 2007; 23:1475-80.

36. Suligoi B, Buttò S, Galli C, Bernasconi D, Salata RA, Tavoschi L, et al. Detection of recent HIV infections in African individuals infected by HIV-1 non-B subtypes using HIV antibody avidity. J Clin Virol 2008; 41:288-92.

37. Wilson KM, Johnson EI, Croom HA, Richards KM, Doughty L, Cunningham PH, et al. Incidence immunoassay for distinguishing recent from established HIV-1 infection in therapy-naive populations. AIDS 2004; 18:2253-9.

38. Barin F, Meyer L, Lancar R, Deveau C, Gharib M, Laporte A, et al. Development and validation of an immunoassay for identification of recent human immunodeficiency virus type 1 infections and its use on dried serum spots. J Clin Microbiol 2005; 43:4441-7.

39. Semaille C, Cazein F, Pillonel J, Lot F, Le Vu S, Pinget $\mathrm{R}$, et al. Four years of surveillance of recent HIV infections at country level, France, mid 2003 - 2006: experience and perspectives. Euro Surveill 2008; 13:pii:18968.

40. Sakarovitch C, Rouet F, Murphy G, Minga AK, Alioum A, Dabis F, et al. Do tests devised to detect recent HIV-1 infection provide reliable estimates of incidence in Africa? J Acquir Immune Defic Syndr 2007; 45:115-22.

41. Schüpbach J, Gebhardt MD, Tomasik Z, Niederhauser C, Yerly S, Bürgisser P, et al. Assessment of recent HIV-1 infection by a line immunoassay for HIV-1/2 confirmation. PLoS Med 2007; 4:e343.

42. Schechter M, Lago RF, Melo MF, Sheppard HW, Guimarães NC, Moreira RI, et al. Identification of a high-risk heterosexual population for HIV prevention trials in Rio de Janeiro, Brazil. Projeto Praça Onze Study Group. J Acquir Immune Defic Syndr 2000; 24:175-7.

43. Barroso PF, Harrison LH, Fátima-Melo M, Batista SM, Silva-Bastos M, Rosa-Faulhaber JC, et al. Identification of a high-risk heterosexual cohort for HIV vaccine efficacy trials in Rio de Janeiro, Brazil, using a sensitive/less-sensitive assay: an update. J Acquir Immune Defic Syndr 2004; 36:880-1.

44. Guimarães ML, Bastos FI, Telles PR, Galvão-Castro B, Diaz RS, Bongertz V, et al. Retrovirus infections in a sample of injecting drug users in Rio de Janeiro City, Brazil: prevalence of HIV-1 subtypes, and co-infection with HTLV-I/II. J Clin Virol 2001; 21:143-51.

45. Teixeira SL, Bastos FI, Telles PR, Hacker MA, Brigido LF, Oliveira CAF, et al. HIV-1 infection among injection and ex-injection drug users from Rio de Janeiro, Brazil: prevalence, estimated incidence and genetic diversity. J Clin Virol 2004; 31:221-6.

46. Diaz RS, Kallas EG, Castelo A, Rawal BD, Busch MP. Use of a new 'less-sensitive enzyme immunoassay' testing strategy to identify recently infected persons in a Brazilian prison: estimation of incidence and epidemiological tracing. AIDS 1999; 13:1417-8.
47. Turchi MD, Diaz RS, Martelli CM, Sabino EC, Silva WP, Filho OF, et al. Genetic diversity and HIV-1 incidence estimation among cocaine users in São Paulo, Brazil. J Acquir Immune Defic Syndr 2002; 30:527-32.

48. Alves K, Shafer KP, Caseiro M, Rutherford G, Falcao ME, Sucupira MC, et al. Risk factors for incident HIV infection among anonymous HIV testing site clients in Santos, Brazil: 1996-1999. J Acquir Immune Defic Syndr 2003; 32:551-9.

49. Kallas EG, Bassichetto KC, Oliveira SM, Goldenberg I, Bortoloto R, Moreno DM, et al. Establishment of the serologic testing algorithm for recent human immunodeficiency virus (HIV) seroconversion (STARHS) strategy in the city of São Paulo, Brazil. Braz J Infect Dis 2004; 8:399-406.

50. Bassichetto KC, Bergamaschi DP, Veras MA, Sucupira MC, Mesquita F, Diaz RS. Estimating HIV-1 incidence using the serologic testing algorithm for recent HIV infections at HIV counseling and testing centers in the city of São Paulo, Brazil. Braz J Infect Dis. 2009; 13:9-12.

51. Freitas-Oliveira CA, Ueda M, Yamashiro R, Rodrigues R, Sheppard HW, Macedo-Brígido LF. Rate and incidence estimates of recent human immunodeficiency virus type 1 infections among pregnant women in São Paulo, Brazil, from 1991 to 2002. J Clin Microbiol 2005; 43:1439-42.

52. Barreto CC, Sabino EC, Gonçalez TT, Laycock ME, Pappalardo BL, Salles NA, et al. Prevalence, incidence, and residual risk of human immunodeficiency virus among community and replacement first-time blood donors in São Paulo, Brazil. Transfusion 2005; 45:1709-14.

53. Sá-Ferreira JA, Brindeiro PA, Chequer-Fernandez S, Tanuri A, Morgado MG. Human immunodeficiency virus- 1 subtypes and antiretroviral drug resistance profiles among drug-naïve Brazilian blood donors. Transfusion 2007; 47:97-102.

54. de Castro CA, Grinsztejn B, Veloso VG, Bastos FI, Pilotto JH, Morgado MG. Prevalence, estimated HIV-1 incidence and viral diversity among people seeking voluntary counseling and testing services in Rio de Janeiro, Brasil. BMC Infect Dis 2010; 10:224.

55. Ferreira JL, Thomaz M, Rodrigues R, Harrad D, Oliveira CM, Oliveira CA, et al. Molecular characterization of newly identified HIV-1 infections in Curitiba, Brazil: preponderance of clade $\mathrm{C}$ among males with recent infections. Mem Inst Oswaldo Cruz 2008; 103:800-8.

56. Brígido LF, Nunes CC, Oliveira CM, Knoll RK, Ferreira JL, Freitas CA, et al. HIV type 1 subtype C and CB Pol recombinants prevail at the cities with the highest AIDS prevalence rate in Brazil. AIDS Res Hum Retroviruses 2007; 23:1579-86.

57. Velasco-de-Castro CA, Grinsztejn B, Veloso V, Bastos F, Pilotto J, Morgado M. Serological approaches to access recent HIV-1 seroconvertion: proposal of criterion to improve the predictive values in BEDCEIA and Avidity Index Assay. AIDS Res Hum Retrov 2008; 24 Suppl 1:S36.

58. Hargrove JW. BED estimates of HIV incidence must be adjusted. AIDS 2009; 23:2061-2. 
59. Welte A, McWalter TA, Bärnighausen T. Reply to 'Should biomarker estimates of HIV incidence be adjusted?'. AIDS 2009; 23:2062-3.

60. McDougal JS. BED estimates of HIV incidence must be adjusted. AIDS 2009; 23:2064-5.

61. Brookmeyer R. Response to correspondence on 'Should Biomarker Estimates of HIV Incidence be Adjusted?'. AIDS 2009; 23:2066-8.

62. McWalter TA, Welte A. A comparison of biomarker based incidence estimators. PLoS One 2009; 4:e7368.

63. Hallett TB, Ghys P, Bärnighausen T, Yan P, Garnett GP. Errors in 'BED'-derived estimates of HIV incidence will vary by place, time and age. PLoS One 2009; 4:e5720.

64. Truong HH, Kellogg T, Louie B, Klausner J, Dilley J, McFarland W. Recent HIV-1infection detection: comparison of incidence estimates derived by laboratory assays and repeat testing data. J Acquir Immune Defic Syndr 2009; 51:502-5.

65. Laeyendecker O, Rothman RE, Henson C, Horne BJ, Ketlogetswe KS, Kraus CK, et al. The effect of viral suppression on cross-sectional incidence testing in the Johns Hopkins hospital emergency department. J Acquir Immune Defic Syndr 2008; 48:211-5.
66. Bello G, Velasco-de-Castro CA, Bongertz V, Rodrigues CA, Giacoia-Gripp CB, Pilotto JH, et al. Immune activation and antibody responses in nonprogressing elite controller individuals infected with HIV-1. J Med Virol 2009; 81:1681-90.

67. World Health Organization. Report of the WHO working group on statistical approaches for development, validation and use of HIV incidence assays. http://www.who.int/diagnostics_laboratory/ links/hiviwg_geneva_04_09_report.pdf (accessed on Apr/2009).

68. Karon JM, Song R, Brookmeyer R, Kaplan EH, Hall HI. Estimating HIV incidence in the United States from HIV/AIDS surveillance data and biomarker HIV test results. Stat Med 2008; 27:4617-33.

69. Hacking I. The taming of chance (ideas in context). Cambridge: Cambridge University Press; 1990.

Submitted on 13/Nov/2009

Final version resubmitted on $22 / \mathrm{Feb} / 2010$

Approved on 12/Mar/2010 